\title{
Suggestions to Alleviate the Financing Risks of Family Farmers: Based on the Investigation Report of Pig Farmers in Jiulongshan Town, Kaizhou District, Chongqing
}

\author{
Xin Gao*, Hong Chen, Yuyi Chen, Yuyang Feng, Zixuan Cai, Hong Cheng \\ Chongqing University of Technology, Chongqing 401320, China. E-mail: 945351717@qq.com
}

\begin{abstract}
In 2013, the Central Document No. 1 first proposed the concept of "family farm". As an important part of rural economic development, family farms have increasingly significant financing risks. The No. 1 document of the 19th National Congress of the Communist Party of China in 2018 proposed a strategy to overcome poverty and achieve rural revitalization. Therefore, it is of great value and significance to study the financing risks of family farmers and explore solutions. This article is based on an in-depth investigation and analysis of the farm development status, land circulation, and mortgage financing of family farm land contract management rights in Jiulongshan Town, Kaizhou District, Chongqing. In addition, it also investigates the implementation and publicity of the financial support policies of rural commercial banks, the Agricultural Bank of China, the Industrial and Commercial Bank of China, and the Postal Savings Bank on family farmer financing. Finally, the existing problems are analyzed and relevant policy suggestions are put forward.
\end{abstract}

Keywords: Family Farm; Financing Risk; Countermeasure; Suggestion

\section{Introduction}

This research combines the theoretical basis of family farm financing and the real experience of financing measures in developed countries, and makes a clear investigation and analysis of the current status and financing risks of family farm financing, and proposes corresponding solutions to the risks of family farm land contractual management right mortgage financing. The state's policy support for banks, the establishment of family farms and inter-bank power mechanisms, etc., to open market channels for family farms and demand sides, and provide a useful reference for banks to share loan risks and solve financing risks for related departments are all investigated.

Survey objects: pig farmers and growers in Jiulongshan Town, Kaizhou District, Chongqing City (main survey villages: Dongba Village, Shuanghe Village, Xinzhai Village, etc.)

Survey method: data collection, interview and questionnaire survey

Survey time: deadline on September 7, 2019

\section{Summary situation of family farms in Jiulongshan Town, Kaizhou District}

The Jiulongshan Town of Kaizhou District has jurisdiction over 17 villages and 2 communities. The total popula-

This is an open-access article distributed under the terms of the Creative Commons Attribution Non-Commercial License (http://creativecommons.org/licenses/by-nc/4.0/), which permits unrestricted non-commercial use, distribution, and reproduction in any medium, provided the original work is properly cited. 
tion is 53,000 , the area is 135 square kilometers, the cultivated area is $60,000 \mathrm{mu}$, and the forest area is $100,000 \mathrm{mu}$. As of September 7, 2019, in the valid questionnaires that have been recovered, $60 \%$ of the family farms have an operating area of less than $30 \mathrm{mu}, 20 \%$ are $30-50 \mathrm{mu}, 10 \%$ are 50-100 mu, and $10 \%$ are $500 \mathrm{mu}$. This effectively shows the differentiation of reasonable business scale. The survey shows that $90 \%$ of family farms have been registered in the industrial and commercial department. Among them, $90 \%$ of family farms are self-employed and $10 \%$ are partnerships (unlimited liability). Family farmers have a long, rich experience in pig farming. The farmers are mainly in the middle of their strong years, and their age distribution is very reasonable. The number of employed workers is relatively small and they are mostly older short-term workers. Jiulongshan Town is rich in geographical resources, and has diverse sales channels for family farm products, including online electronic (or telephone sales) platforms, bazaars, and cooperative organization acquisitions.

\section{Problems in family farm financing in Jiulongshan Town}

In the course of this field investigation, it is found that Jiulongshan Town has issued a lot of policy subsidies on the development of family farms, but there are still many constraints. This has greatly affected the sustainable development of Jiulongshan Town Family Farm.

\subsection{Lack of funds}

From the survey results, it can be seen that $100 \%$ of Jiulongshan Town's family farms have a shortage of funds. The main reason is that family farms have to carry out a series of production and operation activities such as land transfer, site purchase, machinery purchase and production materials at the beginning of the season/year. Both require large amounts of start-up capital.

\subsection{Less financing channels and more difficulties}

The main financing method of Jiulongshan Town family farm is to borrow money from relatives and friends, supplemented by and loans from banks, but the loan share is limited. To support the development of farms, local banks have launched a series of policies, such as: micro-credit loans for farmers, interest-free entrepreneurship loans, and interest-free poverty alleviation loans. However, due to the limitations of the family farm's size and its own credit rating and other specific conditions, most family farmers ultimately choose entrepreneurial loans and poverty alleviation loans with a low interest rate, totaling 150,000 yuan. However, these 150,000 yuan can only serve as a small part of the start-up capital. To obtain a higher loan amount, the farmer needs to provide proof of collateral or real estate, but the local farmer has the problem of not having a real estate certificate. In addition, the financing of land contractual management rights as collateral requires the guarantee company to calculate the output and size of the family farm. In this process, there are many mortgage links, high evaluation costs, and few local family farms that meet the requirements. Family farmers need a lot of money to support production and operation activities, and expand the scale of operations. However, banks have not given loans to small-scale family farmers, which has formed a vicious cycle of unequal supply and demand. Therefore, a single financing channel is insufficient, which is still a very large problem in the development of family farms.

\subsection{The support and publicity of the government and financial institutions are insufficient}

As mentioned above, there is a contradiction between supply and demand between the family farm and the bank in Jiulongshan Town. The reason is that farmers have limited loans due to problems such as scale and credit rating, and banks are also reluctant to bear higher loan risks. For the government, there is also a lack of preferential policies for modern agricultural technical personnel.

On the other hand, the family farms in the area are generally small and medium-sized and do not meet the conditions for mortgage financing. At the same time, although larger-scale farms meet the conditions for loans, the mortgage financing policy for land contractual management rights has not been fully popularized. 


\subsection{Low risk resistance}

\subsubsection{Natural risks}

While the technology of social production and management has improved, the risks borne by the planting and breeding industries in the course of operation have become smaller and smaller. However, in agricultural production, natural risks such as sudden plant diseases and insect pests and the climate and environment have caused a reduction in agricultural production. This creates a natural tension affecting risk assessment.

\subsubsection{Financing risk}

It has been learned from many banks that most family farmers can repay loans with lower amounts and lower interest rates on schedule. If the loan amount is increased, there will be greater risks between farmers and banks. Assuming that during the production and operation process, uncontrollable factors cause the borrower to lose property and fail to repay on time, the bank needs to bear the risks that the collateral cannot be realized and the borrower defaults.

\section{Suggestions}

It can be concluded that the difficulties in financing family farms in my country reflect not only the family farm itself, but also all aspects of the country's agricultural development. Under favorable policy conditions, all parties should promote reform and innovation to fundamentally break the plight of family farm financing. To this end, the following recommendations are made.

\subsection{Exercising government functions}

The government can provide targeted financial support to farmers and explore a large number of agricultural loans. The large loans for farmers, the successful methods of small-scale farmers' loans, and the credit of large-scale farmers can be used to fill the real needs of land circulation capital; establish agricultural guarantee companies that specialize in sharing credit risk services for family farms; and establish loan risk compensation system, and loans issued by financial institutions should be given certain risk compensation to family farm; it is important to optimize the allocation of various types of agriculture and incentive funds, strengthen the credit rating of family farms and provide favorable economic support for family farms ${ }^{[3]}$. It is also important to strongly support bank financial institutions to incorporate family credit rating and credibility into credit management. Finally, the government should provide financial and subsidized employment of high-tech talents to provide theoretical and technical guidance for the development of family farms, and at the same time combine with farmers personal experience, improve the farmer's production and management capabilities, and improve the ability of family farms to avoid risks; public management: the government increases publicity, expands farmers' financing channels, and actively promotes the registration system.

\subsection{Encourage various financial institutions to strongly support family farm financing}

Modern family farms are gradually being modernized and financialized, but in the early stages of development, they were restricted by their own conditions and were severely hindered in all aspects. Family farm financing mainly depends on financial institutions. Therefore, the strong support of financial institutions is of great significance to family farms to solve financing problems. It is also the key to creating a good financial environment, promoting active agricultural investment and promoting modern agricultural development.

\subsubsection{Lower loan interest rates and simplify loan procedures}

The development of society, rising prices, and rising cost of human resources all make family farmers requiring a lot of capital in the early stages of development, and bear natural and market risks. It is difficult for financial institutions to have a high degree of trust in family farmers, and other organizations have little investment in agriculture, which makes it difficult for family farms to withstand higher interest rate losses ${ }^{[4]}$. Therefore, banks and credit unions involved 
in agriculture can give the agricultural market an easy financing environment by lowering the loan interest rate and simplifying the loan procedures.

\subsubsection{Create multiple financing supply channels}

Family farms can transfer land during the financing process and purchase production materials seasonally. Therefore, family farms have the characteristics of diversity and cycle diversification in the financing process. Taking into account the characteristics of family farm financing, relevant financial institutions can launch various financing supply channels and establish differential loan policies. For families with better credit, they can also consider adopting credit loan policies.

\subsubsection{Establish a comprehensive agricultural insurance policy}

The development of insurance in the agricultural market is not yet perfect, and insurance companies are not enthusiastic about agricultural insurance. China is a large agricultural development country, but at the same time, due to the rapid development of the country's economic strength, the country's agricultural insurance development is not mature, and current insurance products are unable to meet existing needs. Therefore, insurance companies can develop more agricultural insurance products to ensure the stable development of family farms, which plays an important role in family farms.

\subsubsection{Relax the restrictions on collateral}

Family farmers generally have a small amount of their own funds that can be mortgaged. However, the current problem is that some legal provisions and bank's mortgage policies do not support farmers and farms to mortgage land contractual management rights or have higher thresholds for this. Rural housing's liquidity in China is not enough and make it difficult to monetize, which leads to the lack of effective guarantee conditions for family farmers and the reluctance of banks to bear the risk that they cannot repay their loans on time. Therefore, the bank can relax the conditions of the farm house mortgage, and at the same time, the government can clarify the rights and interests of rural assets, such as clarifying the right to land contractual management rights and issuing real estate certificates for farm houses, so that family assets can be reasonably monetized and reduce the risk of bank loans.

\subsubsection{Provide more considerate financial services}

With the market-oriented reform of finance, many state-owned commercial banks and rural credit cooperatives have withdrawn their outlets from rural areas. The financial service industry is becoming more and more urban-oriented, and fewer and fewer service outlets can meet rural finance. Therefore, various financial institutions should add more rural outlets to provide family farms with more appropriate financing suggestions, provide more favorable loan methods, and more importantly, it is important to do a good job of family farm financing promotion so that family farmers can have channels and ways to obtain Financing message.

\subsection{Encourage civil society to actively participate}

When the government promotes the development of family farms, civil society organizations can be used to accelerate the development of family farms. In addition, government authorities also need to play a guiding and controlling role in the development of civil organizations. At the same time, fast-growing civil organizations will also contribute to the rapid progress of family farms. This can form a beneficial circular development. Civil organizations can also form an order production model with family farms, which not only shares the production risk of family farms, but also mobilizes the enthusiasm of family farms for production, and also solves part of the financing problems of family farmers ${ }^{[2]}$. Therefore, on the basis of this win-win model of cooperation between family farms and civil organizations, a form of combination of capital cooperation and production cooperation was formed.

\subsection{Improve farmer's financing ability from multiple angles}

\subsubsection{UNPROFOR loan}


UNPROFOR loans are a new type of loan mechanism derived by the government in order to vigorously promote the development of family farms with low interest rates, low application thresholds, and high loan quotas ${ }^{[3]}$. This mechanism not only strengthens the cooperation between family farmers, but also promotes family farmers.

\subsubsection{Government training}

Faced with the current situation of family farmers lacking financial knowledge, the government should provide corresponding financial training and agricultural technology training to improve family farmers' knowledge reserves in this area through secondary learning. Including through the establishment of entrepreneurship training, economic management training, providing an open education and learning platform, etc., various ways to improve the education level of family farmers to promote the sustainable development of family farms.

\subsubsection{The farmer himself}

In addition to knowledge training organized by the government, through online books, periodicals, etc., farmers can also enhance their knowledge reserves and their own management capabilities. Work hard to learn and innovate in concept and technology, constantly improve own quality, and enhance the overall credit image of family farms in financial institutions.

\section{Conclusion}

In general, under the trend of socialist market economy, family farms are still a disadvantaged group. It is a manifestation of farmers' affirmation and support for the development of agricultural modernization that individual farmers take loans and take risks for family farms. At the same time, it actively strives for the cooperation between the farmers and the government and financial institutions to build a dynamic mechanism between the family farm, the bank and the government to give the family farm a good financial support. Moreover, in order to accelerate the development of stable family farms, the government should adopt a more inclined policy. Today, support for family farm finance has gradually entered the public's field of vision. The public also pays more and more attention to the role of finance in the development of family farms. Policy makers and family farmers themselves also focus on how to solve the dilemma in the development of family farms. However, the family farm model is only on the right track, and there is still a lack of systematic empirical research ${ }^{[4]}$. Therefore, systematically and theoretically studying China's family farm financial support system can help promote the healthy and rapid development of family farms, and at the same time can promote the vigorous development of China's economy.

\section{Acknowledgement}

This project is funded by Chongqing University of Science and Technology's undergraduate research project.

\section{References}

1. Zhu M. An analysis of the risks of family farm financing in my country: Taking Zhejiang Province as an Example (in Chinese). SME Management and Technology (Early Issue) 2015; (4): 106-107.

2. Guo Y. Research on family farm financing (in Chinese). Southern Finance 2013; (3): 59-61. doi: 10.3969/j.issn.1007-9041.2013.03.012.

3. Fang Y. Analysis of the financing plight of family farms in Henan Province (in Chinese). Modern Economic Information 2016; (18): 477-478.

4. Lan Y, Zhou M, Yi Z. Research on financial support for family farms in China (in Chinese). Agricultural Technology and Economy 2015; (6): 48-56. 